\title{
Germacrone induces lung cancer cell apoptosis and cell cycle arrest via the Akt/MDM2/p53 signaling pathway
}

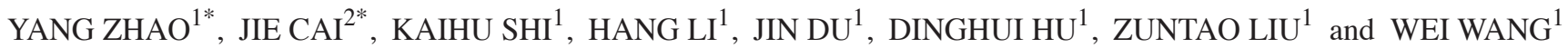 \\ ${ }^{1}$ Department of Cardiothoracic Surgery, Affiliated Hospital of Integrated Traditional Chinese and \\ Western Medicine, Nanjing University of Chinese Medicine, Nanjing, Jiangsu 211800; \\ ${ }^{2}$ Department of Infectious Diseases, The First Affiliated Hospital of \\ Nanjing Medical University, Nanjing, Jiangsu 210029, P.R. China
}

Received November 5, 2020; Accepted January 28, 2021

DOI: $10.3892 / \mathrm{mmr} .2021 .12091$

\begin{abstract}
Germacrone (GM) displays a wide range of antitumor, antioxidant and anti-inflammatory effects; however, to the best of our knowledge, the effects of GM on lung cancer cell apoptosis and cell cycle arrest have not been previously reported. The aim of the present study was to investigate discussed the effects of GM on the apoptosis and cycle arrest of lung cancer cells. Cell viability, proliferation and apoptosis were assessed by performing Cell Counting Kit-8, colony formation and TUNEL assays, respectively. Western blotting was performed to detect the expression levels of apoptosis-, cell cycle- and Akt/MDM2 proto-oncogene (MDM2)/p53 signaling pathway-related proteins. Compared with the control group, 50, 100 and $200 \mu \mathrm{M}$ GM significantly inhibited lung cancer cell proliferation, but significantly induced cell apoptosis and $\mathrm{G}_{1} / \mathrm{S}$ cell cycle arrest. GM also significantly altered the expression levels of Akt/MDM2/p53 signaling pathway-related proteins compared with the control group. Administration of Akt activator SC79 significantly reversed GM-mediated antiproliferative, proapoptotic and pro-cell cycle arrest effects in lung cancer cells. Therefore, the results of the present study demonstrated that GM induced lung cancer cell apoptosis and cell cycle arrest via the Akt/MDM2/p53 signaling pathway.
\end{abstract}

\section{Introduction}

Lung cancer is the most common malignant tumor worldwide. With increased industrialization, air quality around the

Correspondence to: Dr Yang Zhao, Department of Cardiothoracic Surgery, Affiliated Hospital of Integrated Traditional Chinese and Western Medicine, Nanjing University of Chinese Medicine, 100 Hongshan Cross Street, Qixia, Nanjing, Jiangsu 211800, P.R. China

E-mail: yangzhaozy@163.com

*Contributed equally

Key words: germacrone, lung cancer, apoptosis, cycle arrest, Akt/MDM2 proto-oncogene/p53 signaling pathway world has been reduced to varying degrees (1). The incidence of lung cancer remains high, with a 5-year survival rate of 16-18\% worldwide (2). Lung cancer can be divided into small cell lung cancer and non-small cell lung cancer (NSCLC), which accounts for $85 \%$ of all lung cancer cases, according to pathological morphology and the degree of differentiation (3). Therefore, investigating the pathogenesis of NSCLC and identifying novel therapeutic drugs and targets for the disease is important.

Germacrone (GM), a natural product isolated from the traditional Chinese medicine zedoary, displays a wide range of pharmacological functions, including antitumor (4), antioxidation (5) and anti-inflammation activities (6). In addition, it has been reported that GM displays antitumor activity in vitro (7). GM induces prostate cancer cell apoptosis and autophagy by inhibiting the Akt/mTOR signaling pathway (8). GM also serves an anticancer role by inducing $\mathrm{G}_{2} / \mathrm{M}$ phase cell cycle arrest and promoting apoptosis in gastric cancer cells (4). Furthermore, GM inhibits breast cancer cell line proliferation by inducing cell cycle arrest at the $\mathrm{G}_{0} / \mathrm{G}_{1}$ and $\mathrm{G}_{2} / \mathrm{M}$ phases, and promoting cell apoptosis (9). An et al (10) demonstrated that GM displays a significant protective effect against lipopolysaccharide-induced acute lung injury in neonatal rats. However, to the best of our knowledge, the effect of GM on lung cancer has not yet been reported.

A previous study revealed that zedoary inhibits tumor cell proliferation, invasion and migration by inhibiting the Akt signaling pathway, suggesting a potential antitumor mechanism (11). The Akt/MDM2 proto-oncogene (MDM2)/p53 signaling pathway serves an important role in the regulation of apoptosis and proliferation $(12,13)$. The Akt signaling pathway is a classic intracellular signaling pathway that causes tumorigenesis via a range of mechanisms $(14,15)$. The malignancy of numerous different types of cancer, including lung cancer, is associated with increased abnormal activity of the Akt signaling pathway (16-18). Akt phosphorylates the p53 suppressor MDM2 and promotes MDM2 to translocate to the nucleus, thereby inhibiting the function of p53 (19).

Therefore, the present study investigated the role of GM in lung cancer cells and its underlying molecular mechanism, with the aim of providing a theoretical basis for the treatment of lung cancer. 
A

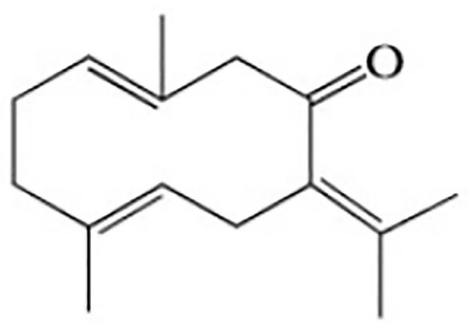

B

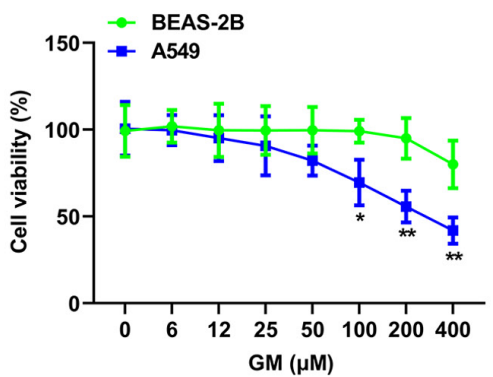

C

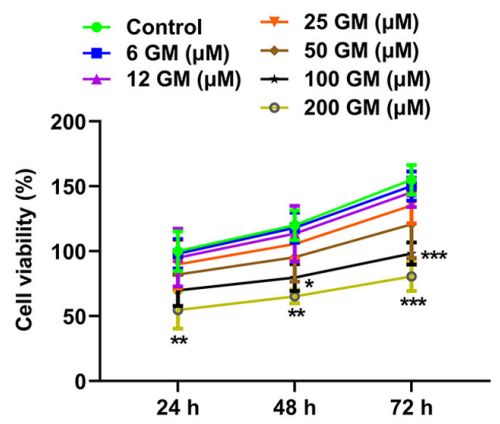

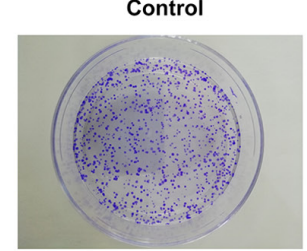

$100 \mathrm{GM}(\mu \mathrm{M})$

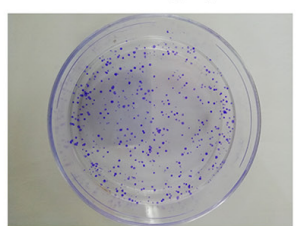

$50 \mathrm{GM}(\mu \mathrm{M})$

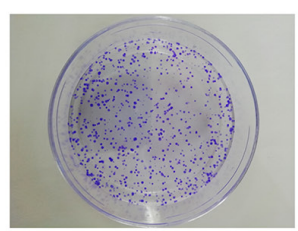

$200 \mathrm{GM}(\mu \mathrm{M})$

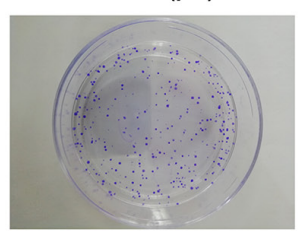

$\mathbf{E}$

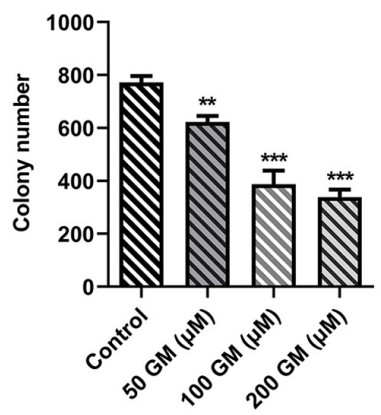

Figure 1. GM inhibits lung cancer cell proliferation. (A) Chemical structure of GM. (B) Effect of different concentrations of GM on BEAS-2B and A549 cell viability $(\mathrm{n}=5)$. ${ }^{*} \mathrm{P}<0.05$ and ${ }^{* * *} \mathrm{P}<0.001$ vs. BEAS-2B. (C) Effect of different concentrations of GM on A549 cell viability at 24,48 and $72 \mathrm{~h}(\mathrm{n}=5)$. ${ }^{*} \mathrm{P}<0.05$, ${ }^{* *} \mathrm{P}<0.001$ and ${ }^{* * * *} \mathrm{P}<0.001$ vs. Control. (D) Cell proliferation was detected by performing colony formation assays (magnification, $\mathrm{x} 10$ ). (E) Statistical analysis of $\mathrm{D}(\mathrm{n}=3) .{ }^{* *} \mathrm{P}<0.001$ and ${ }^{* * *} \mathrm{P}<0.001$ vs. control. GM, germacrone.

\section{Materials and methods}

Cell culture. The human bronchial epithelial cell line (BEAS-2B) and lung cancer cell line (A549) were purchased from The Cell Bank of Type Culture Collection of The Chinese Academy of Sciences. Cells were cultured in DMEM (Gibco; Thermo Fisher Scientific, Inc.) supplemented with 10\% FBS (Gibco; Thermo Fisher Scientific, Inc.) at $37^{\circ} \mathrm{C}$ with $5 \% \mathrm{CO}_{2}$. Cells were cultured with different concentrations $(6,12,25,50$, 100,200 and $400 \mu \mathrm{M}$ ) of $\mathrm{GM}$ for $48 \mathrm{~h}$ at $37^{\circ} \mathrm{C}$ (purity $>98 \%$; Shanghai YuanYe Biotechnology Co., Ltd.). Cells in the control group were treated with equal concentrations of DMEM.

Cell Counting Kit-8 (CCK-8) assay. A549 cell viability was assessed by performing the CCK- 8 assay (Beyotime Institute of Biotechnology). Following treatment, $10 \mu \mathrm{l}$ CCK-8 solution was added to each well and incubated for $4 \mathrm{~h}$ at $37^{\circ} \mathrm{C}$. Absorbance was measured at a wavelength of $450 \mathrm{~nm}$ using a microplate reader.

Colony formation assay. Cells were seeded $\left(5 \times 10^{2}\right.$ cells/well) into 6-well plates. Following incubation for 15 days at $37^{\circ} \mathrm{C}$, visible colonies were fixed with $4 \%(\mathrm{w} / \mathrm{v})$ paraformaldehyde for $15 \mathrm{~min}$ at room temperature and stained with crystal violet for $5 \mathrm{~min}$ at room temperature. Stained colonies ( $\geq 50$ cells) were visualized using a light microscope (magnification, x100, Olympus Corporation) equipped with a ColorView II Soft Imaging System digital camera (Olympus Corporation).

TUNEL assay. Cell apoptosis was assessed by performing the Click-iT ${ }^{\circledR}$ TUNEL Alexa Fluor ${ }^{\circledR}$ Imaging assay (Invitrogen; Thermo Fisher Scientific, Inc.). Cells were fixed with
4\% paraformaldehyde for $30 \mathrm{~min}$ at room temperature and then washed with PBS. Subsequently, 0.3\% Triton X-100 in PBS was added and incubated for $5 \mathrm{~min}$ at room temperature. Cells were stained with DAPI at room temperature for $10 \mathrm{~min}$ (Thermo Fisher Scientific, Inc.). A total of $50 \mu \mathrm{l}$ TUNEL reaction mixture was added for $1 \mathrm{~h}$ at $37^{\circ} \mathrm{C}$. Cells were sealed with anti-fluorescence quenched sealing solution and FITC-labeled TUNEL-positive cells were visualized in three randomly selected fields of view using an IX70 confocal microscope (Olympus Corporation) at x20 magnification. To calculate the proportion of apoptotic cells, the number of apoptotic cells and the number of total cells were counted.

Western blotting. The effect of GM treatment on the expression levels of apoptosis-related proteins was determined via western blotting. Briefly, total protein was extracted from cells using RIPA buffer (Nantong Chem-Base Co., Ltd.). Following centrifugation at $300 \mathrm{xg}$ at $4^{\circ} \mathrm{C}$ for $5 \mathrm{~min}$, protein concentrations were determined using a BCA kit (Nantong Chem-Base Co., Ltd.). Proteins (40 $\mu \mathrm{g} /$ lane) were separated via $10 \%$ SDS-PAGE and transferred to PVDF membranes (Bio-Rad Laboratories, Inc.). Following blocking with $5 \%$ skimmed milk for $2 \mathrm{~h}$ at $37^{\circ} \mathrm{C}$, the membranes were incubated overnight at $4^{\circ} \mathrm{C}$ with the following primary antibodies (all Abcam): Anti-Bcl-2 (1:1,000; cat. no. ab32124), anti-Bax (1:1,000; cat. no. ab182733), anti-cleaved (C)-caspase 3 (1:1,000; cat. no. ab32042), anti-caspase 3 (1:1,000; cat. no. ab13847), anti-C-poly(ADP-ribose) polymerase (PARP; 1:1,000; cat. no. ab32064), anti-PARP (1:1,000; cat. no. ab191217), anti-Cyclin D1 (1:1,000; cat. no. ab16663), anti-CDK4 (1:1,000; cat. no. ab108357), anti-CDK6 (1:1,000; 
A
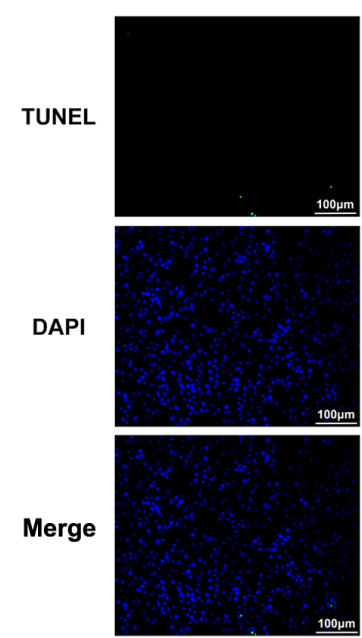

C

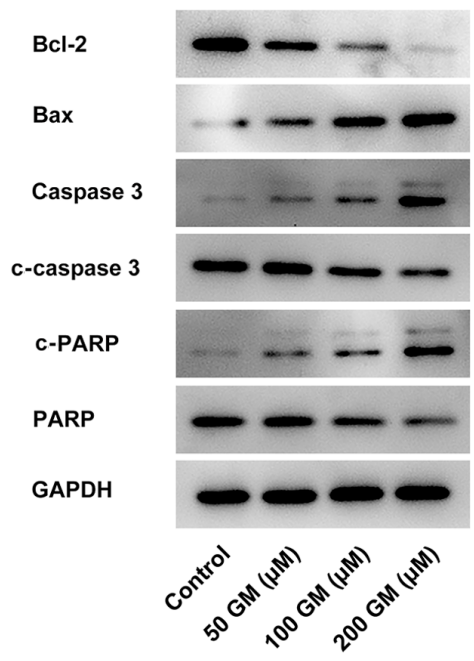

$50 \mathrm{GM}(\mu \mathrm{M})$
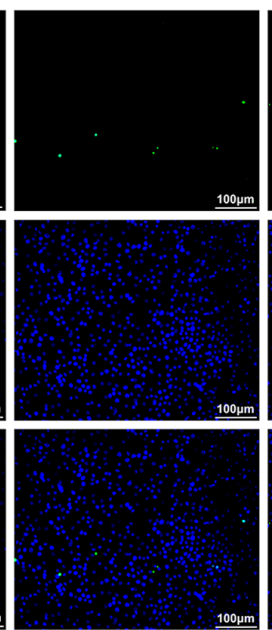

$100 \mathrm{GM}(\mu \mathrm{M})$
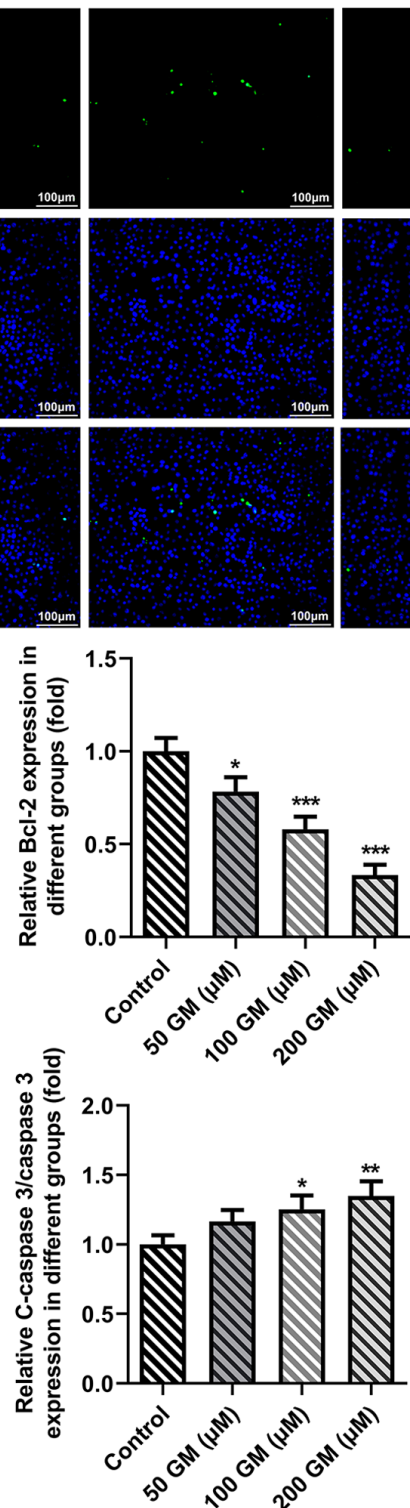

$200 \mathrm{GM}(\mu \mathrm{M})$

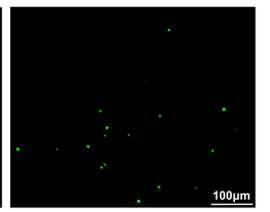

B

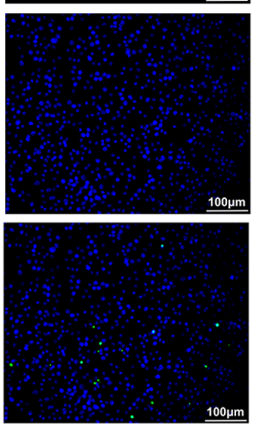

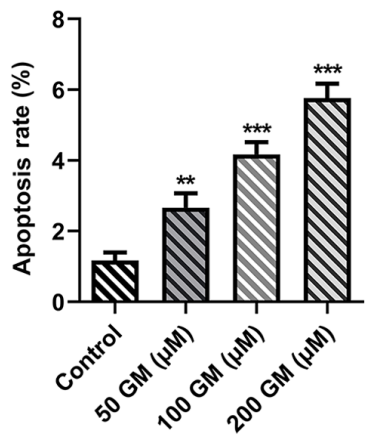

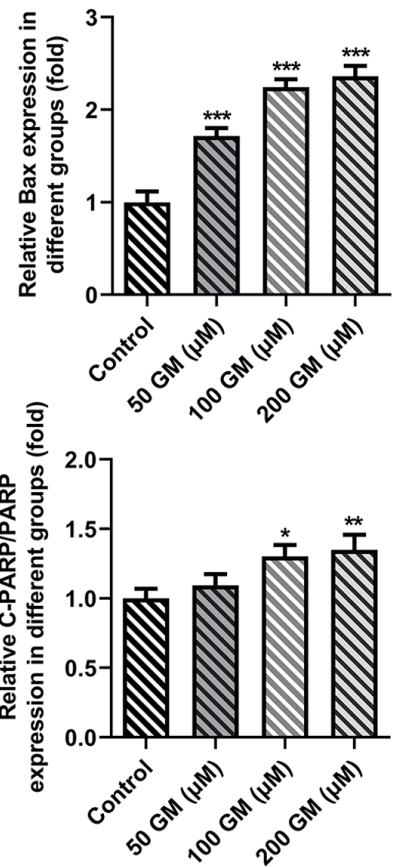

Figure 2. GM induces lung cancer cell apoptosis. A549 cell apoptosis was (A) detected by performing TUNEL assays and (B) quantified (n=3). (C) Expression levels of apoptosis-related proteins were detected via western blotting $(\mathrm{n}=3)$. ${ }^{*} \mathrm{P}<0.05,{ }^{* *} \mathrm{P}<0.001$ and ${ }^{* * *} \mathrm{P}<0.001$ vs. control. GM, germacrone; $\mathrm{C}$, cleaved; $\mathrm{PARP}$, poly(ADP-ribose) polymerase.

cat. no. ab124821), anti-p-Akt (1:1,000; cat. no. ab38449), anti-Akt (1:1,000; cat. no. ab8805), anti-p-MDM2 (1:1,000; cat. no. ab22710), anti-MDM2 (1:1,000; cat. no. ab16895), anti-p53 (1:1,000; cat. no. ab26) and anti-GAPDH (1:1,000; cat. no. ab9485). Subsequently, the membranes were incubated with the corresponding secondary antibody $(1: 5,000$; cat. no. ab150077; Abcam) for $2 \mathrm{~h}$ at $37^{\circ} \mathrm{C}$. Subsequently, the membranes were incubated with goat anti-rabbit horseradish peroxidase-conjugated $\mathrm{IgG}$ secondary antibodies (1:5,000; cat. no. ab150077; Abcam). Protein bands were visualized using the HRP-ECL system (Nantong Chem-Base Co., Ltd.). ImageJ software (version 146; National Institutes of Health) was used to analyze the fold change in protein levels.

Flow cytometry. Cell cycle was detected by EzCell ${ }^{\mathrm{TM}}$ Cell Cycle Analysis kit (cat. no. K920-100; BioVision, Inc.). A549 cells $\left(5 \times 10^{2}\right.$ cells/well) were synchronized in serum-free medium for $24 \mathrm{~h}$. Subsequently, cells were treated with $8 \mu \mathrm{g} / \mathrm{ml}$ SC79 (cat. no. ab146428; Abcam) or GM (50, 100 or $200 \mu \mathrm{M})$ at $37^{\circ} \mathrm{C}$ for $24 \mathrm{~h}$. Cells in the control group were treated with equal concentrations of DMEM. Following washing twice with PBS, cells were trypsinized and collected by centrifugation at $300 \mathrm{x} \mathrm{g}$ at $4^{\circ} \mathrm{C}$ for $5 \mathrm{~min}$, followed by fixation with $70 \%$ ethanol at $4^{\circ} \mathrm{C}$ for $24 \mathrm{~h}$. After washing with PBS, cells were stained with PI in staining solution supplemented with RNase A for $30 \mathrm{~min}$ at room temperature. The cell cycle was assessed using the FACScan flow cytometer (BD Biosciences) and analyzed using CellQuest software (version 7.6.1; Flow Jo LLC.).

Statistical analysis. Statistical analyses were performed using SPSS software (version 13.0; SPPS, Inc.). Data are presented as the mean \pm standard deviation. Comparisons among multiple groups were analyzed using one-way ANOVA followed by 

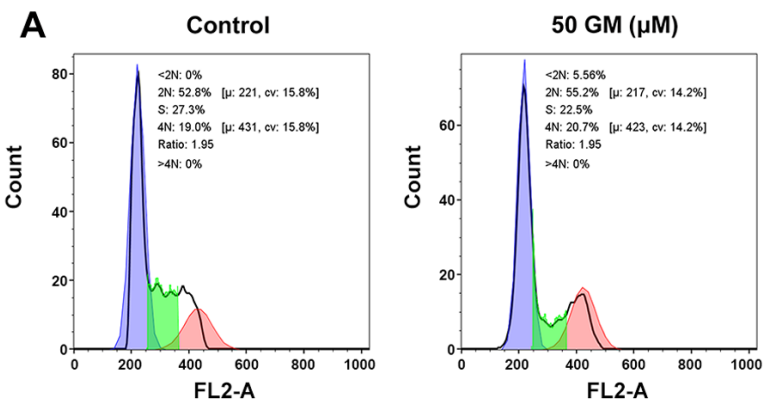

\section{B}
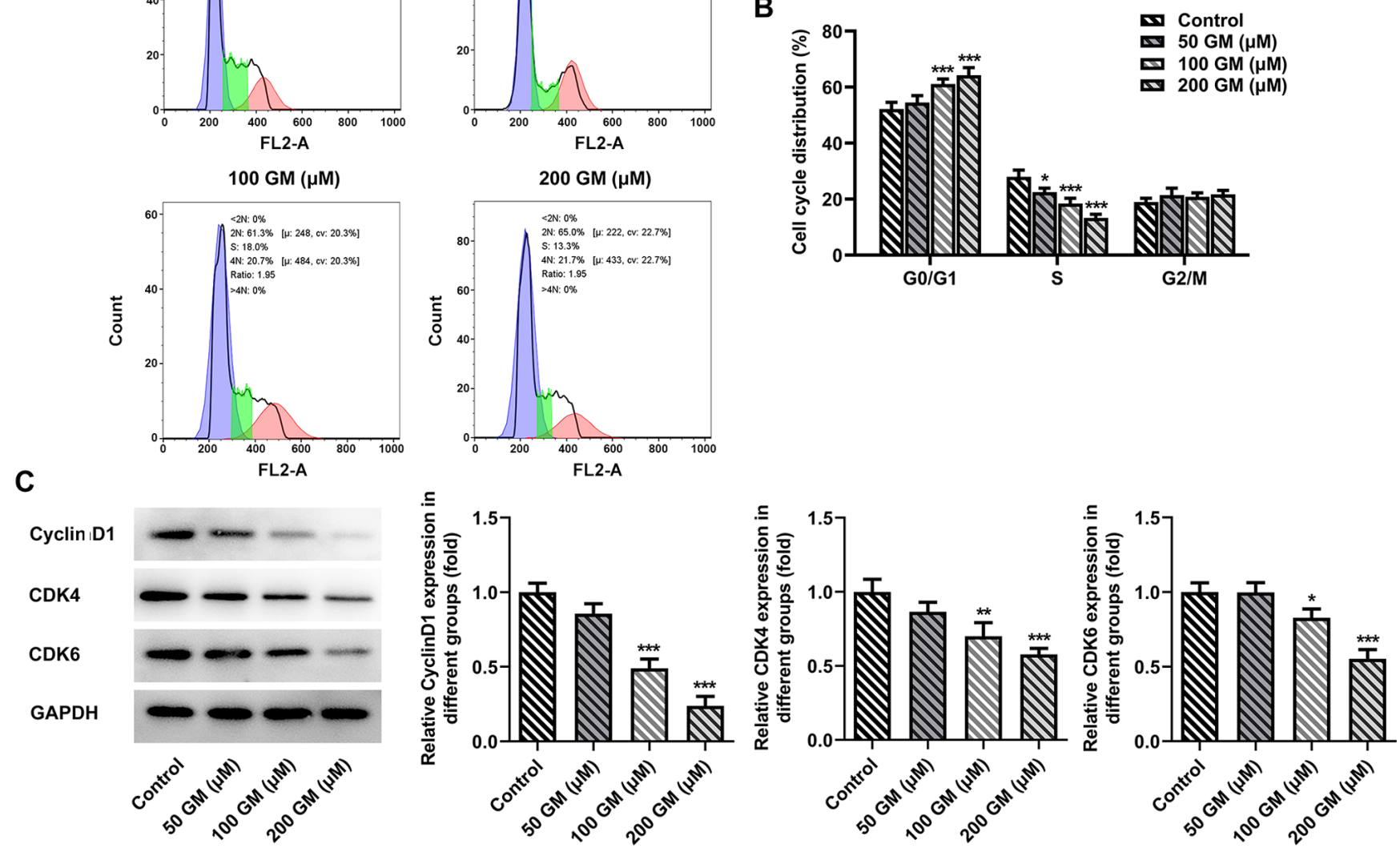

Figure 3. GM induces lung cancer cell $\mathrm{G}_{1} / \mathrm{S}$ phase cell cycle arrest. Cell cycle distribution was (A) determined via flow cytometry and (B) quantified (n=3). (C) Expression levels of cell cycle-related proteins were determined via western blotting $(\mathrm{n}=3)$. ${ }^{*} \mathrm{P}<0.05,{ }^{* * *} \mathrm{P}<0.001$ and ${ }^{* * * *} \mathrm{P}<0.001$ vs. control. GM, germacrone.

Tukey's post hoc test. $\mathrm{P}<0.05$ was considered to indicate a statistically significant difference.

\section{Results}

GM inhibits lung cancer cell proliferation. The chemical formula of GM is presented in Fig. 1A. The CCK- 8 assay was performed to evaluate the effect of different concentrations of $\mathrm{GM}(0,6,12,25,50,100,200$ and $400 \mu \mathrm{M})$ on cell viability $(20,21)$. Cell viability was markedly decreased by GM treatment in a concentration-dependent manner, with the effects of GM on A549 cell viability being more obvious compared with BEAS-2B cell viability (Fig. 1B). Subsequently, A549 cells were treated with different concentrations of GM for 24, 48 or $72 \mathrm{~h}$ (Fig. 1C). The results demonstrated that A549 cell proliferation was significantly decreased by GM treatment $(200 \mu \mathrm{M})$ at $24 \mathrm{~h}$ compared with the control group. Therefore, cells were treated with 50,100 or $200 \mu \mathrm{M}$ GM for $24 \mathrm{~h}$ for subsequent experiments. The colony formation assay results demonstrated that cell proliferation was significantly decreased by GM treatment in concentration-dependent manner compared with the control group (Fig. 1D and E).

GM induces lung cancer cell apoptosis and $G_{I} / S$ cycle arrest . Cell apoptosis was detected by performing TUNEL assays.
The results demonstrated that cell apoptosis was significantly increased by GM treatment in a concentration-dependent manner compared with the control group (Fig. 2A and B). Moreover, GM-treated cells (100 and $200 \mu \mathrm{M})$ displayed significantly increased expression levels of apoptosis-related proteins, including Bax, c-caspase 3 and c-PARP, and significantly decreased expression levels of Bcl-2 compared with the control group (Fig. 2C). The cell cycle was detected via flow cytometry. The results indicated that the proportion of GM-induced lung cancer cells $(50,100$ and $200 \mu \mathrm{M})$ arrested in the $G_{1} / S$ cell cycle phase was significantly increased compared with the control group (Fig. 3A and B). Subsequently, western blotting was performed to detect the expression levels of cell cycle-related proteins, including cyclin D1, CDK4 and CDK6. Compared with the control group, the expression levels of cyclin D1, CDK4 and CDK6 following treatment with 100 or $200 \mu \mathrm{M}$ GM were significantly downregulated in a concentration-dependent manner (Fig. 3C). Collectively, the aforementioned results indicated that GM induced lung cancer cell apoptosis and $\mathrm{G}_{1} / \mathrm{S}$ phase cell cycle arrest.

GM alters the Akt/MDM2/p53 signaling pathway. Compared with the control group, the expression levels of phosphorylated (p)-Akt and p-MDM2 were significantly decreased, 

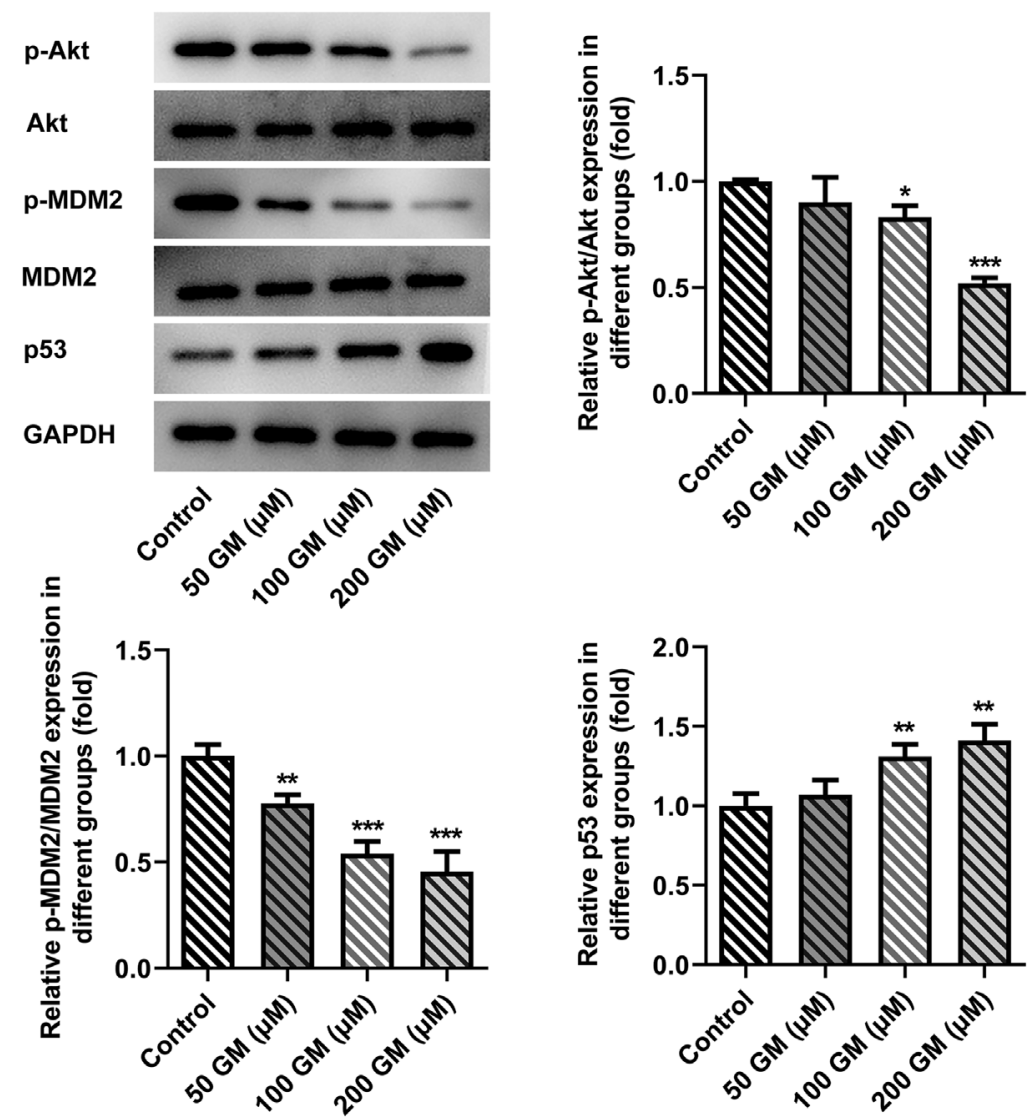

Figure 4. GM alters the Akt/MDM2/p53 signaling pathway. Expression levels of Akt/MDM2/p53 signaling pathway-related proteins were detected via western blotting $(\mathrm{n}=3) .{ }^{*} \mathrm{P}<0.05,{ }^{* * *} \mathrm{P}<0.001$ and ${ }^{* * *} \mathrm{P}<0.001$ vs. control. GM, germacrone; MDM2, MDM2 proto-oncogene; $\mathrm{p}$, phosphorylated.

B

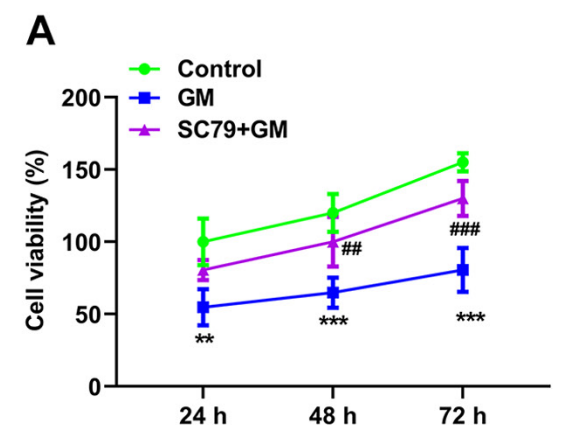

Control

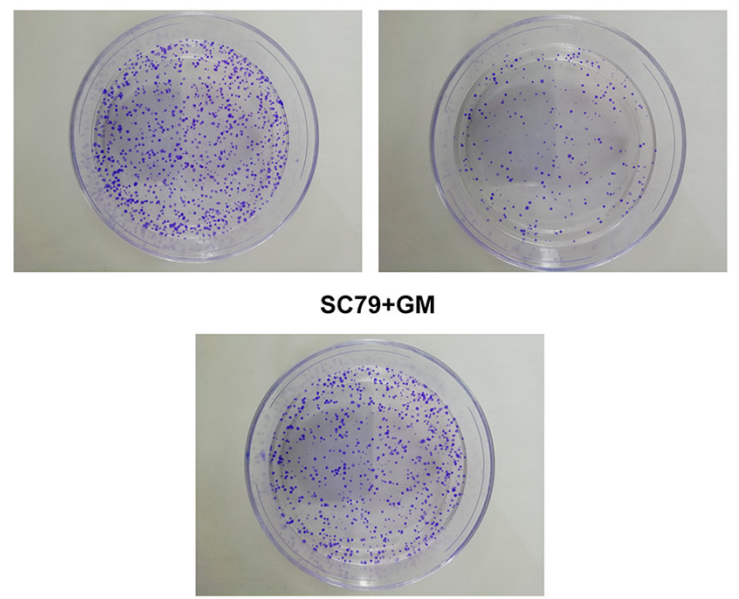

C

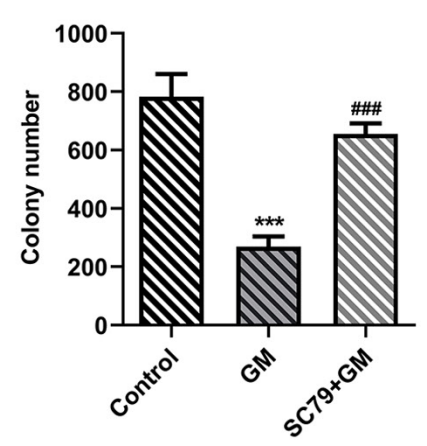

Figure 5. SC79 reverses the antiproliferative effects of GM on lung cancer cells. (A) Effect of SC79 on GM-mediated inhibition of A549 cell viability at 24,48 or $72 \mathrm{~h}(\mathrm{n}=5)$. Cell proliferation was (B) detected by performing colony formation assays (magnification, $\mathrm{x} 10)$ and $(\mathrm{C})$ quantified $(\mathrm{n}=3) .{ }^{* *} \mathrm{P}<0.01$, ${ }^{* * *} \mathrm{P}<0.001$ vs. control; ${ }^{\# \#} \mathrm{P}<0.01,{ }^{\# \#} \mathrm{P}<0.001$ vs. GM. GM, germacrone.

and the expression levels of p53 were significantly increased following 100 and $200 \mu \mathrm{M}$ GM administration (Fig. 4). Therefore, the results indicated that GM altered the Akt/MDM2/p53 signaling pathway. The most notable effects on protein expression were observed following treatment with $200 \mu \mathrm{M} \mathrm{GM}$, so this concentration was selected for subsequent experiments.
SC79 reverses the antiproliferative, proapoptotic and pro-cell cycle arrest effects of GM on lung cancer cells. To further verify the aforementioned results, cells were treated with Akt activator SC79. Cells were divided into the following two groups: i) GM; and ii) SC79+GM. The CCK-8 (Fig. 5A) and colony formation (Fig. 5B and C) assay results demonstrated that cell viability (at 48 and $72 \mathrm{~h}$ ) 
A

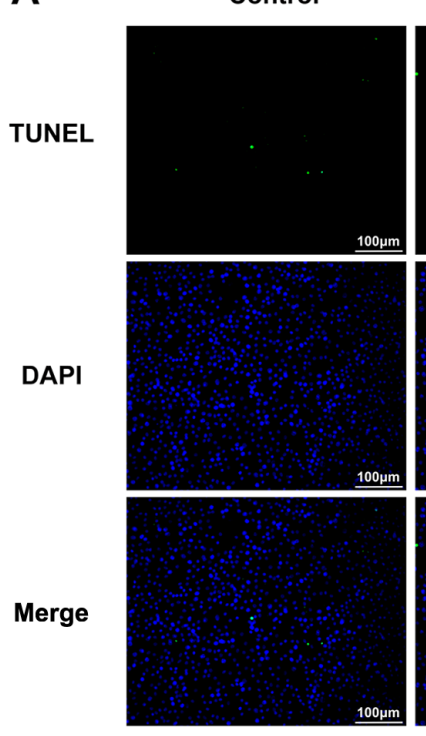

B

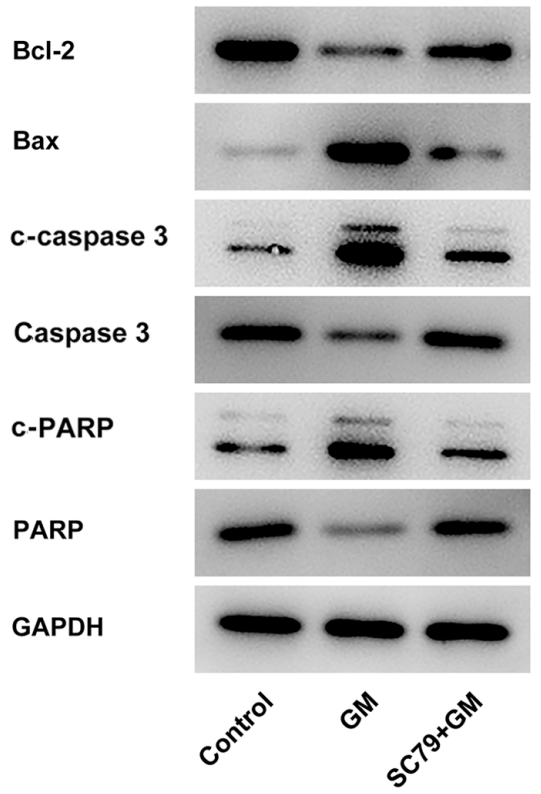

GM
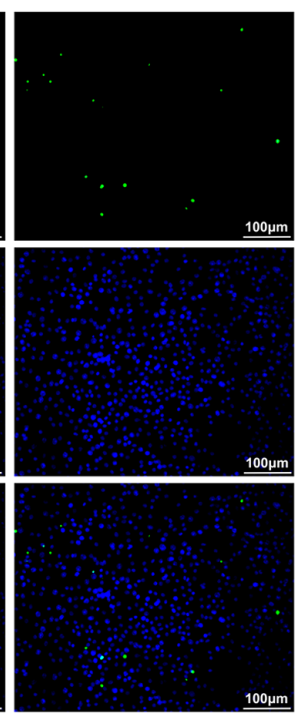

SC79+GM
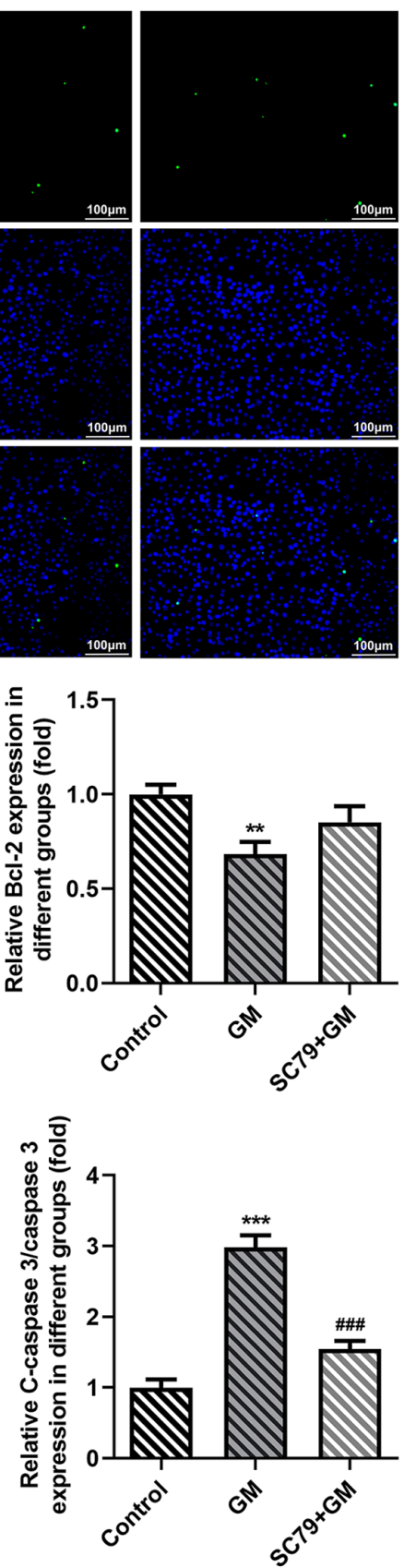
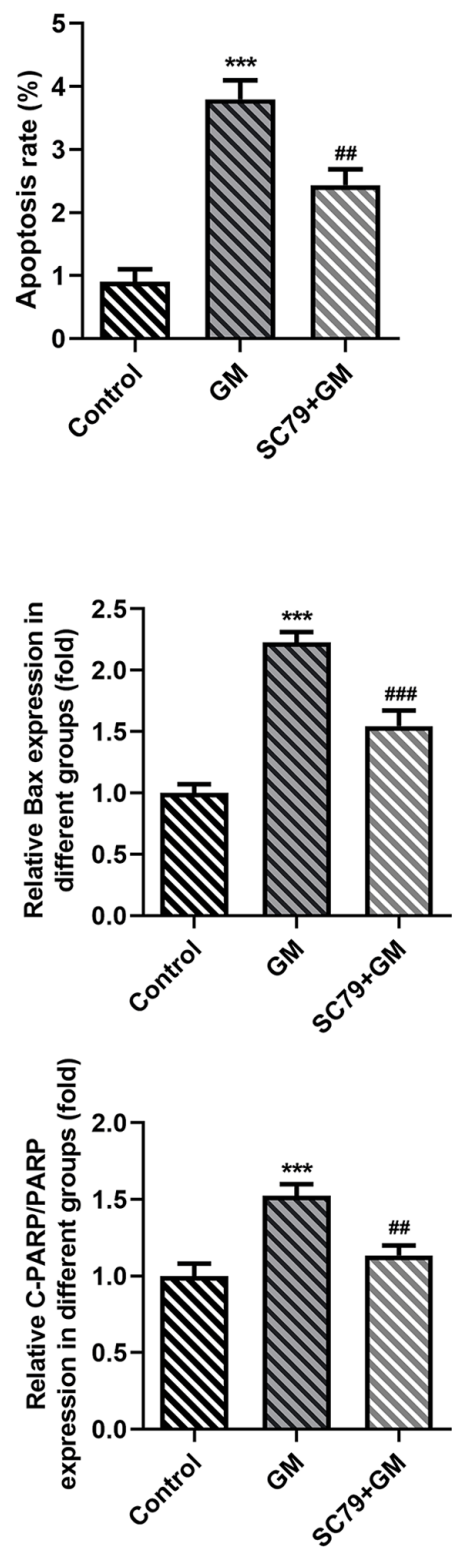

Figure 6. SC79 reverses the proapoptotic effects of GM on lung cancer cells. A549 cell apoptosis was (A) detected by performing TUNEL assays and quantified $(\mathrm{n}=3)$. (B) Expression levels of apoptosis-related proteins were detected via western blotting $(\mathrm{n}=3)$. ${ }^{* *} \mathrm{P}<0.01$ and ${ }^{* * *} \mathrm{P}<0.001$ vs. control. ${ }^{\# \#} \mathrm{P}<0.01$ and

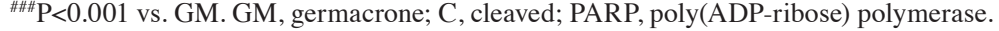

and proliferation were significantly increased in the SC79+GM group compared with the GM group, respectively. Cell apoptosis was detected by performing TUNEL assays. Compared with the GM group, the apoptosis rate of the SC79+GM group was significantly decreased (Fig. 6A). Furthermore, compared with the GM group, the SC79+GM group displayed significantly decreased expression levels of Bax, C-Caspase 3 and c-PARP, and slightly increased expression levels of Bcl-2 (Fig. 6B). The flow cytometry results demonstrated that SC79 significantly reversed GM-induced $\mathrm{G}_{1} / \mathrm{S}$ phase cell cycle arrest (Fig. 7A and B). Subsequently, western blotting was performed to detect the expression levels of cyclin D1, CDK4 and CDK6. Compared with the GM group, the expression levels of cyclin D1, CDK4 and CDK6 in the SC79+GM group were significantly increased (Fig. 7C). In addition, the expression levels of Akt/MDM2/p53 signaling pathway-related proteins were detected. The results demonstrated that p-Akt and p-MDM2 expression levels were significantly upregulated, and p53 expression levels were significantly downregulated in the SC79+GM group compared with the GM group (Fig. 8). Collectively, the results demonstrated that SC79 reversed the antiproliferative, proapoptotic and pro-cell cycle arrest effects of GM on lung cancer cells. 

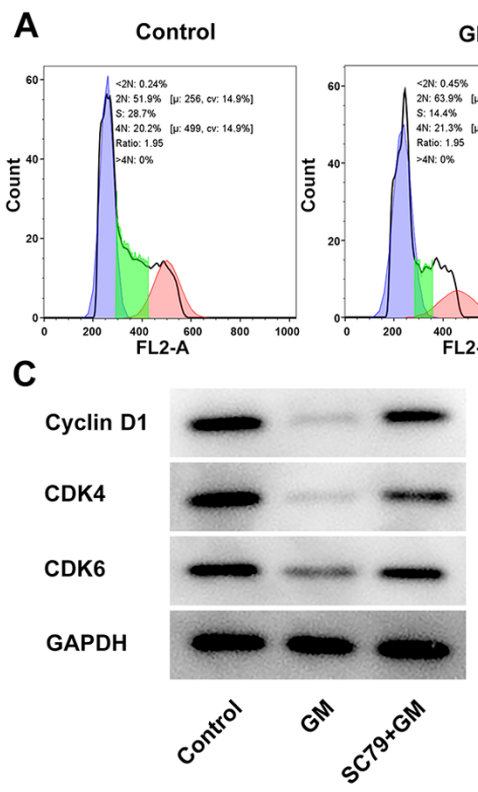

GM
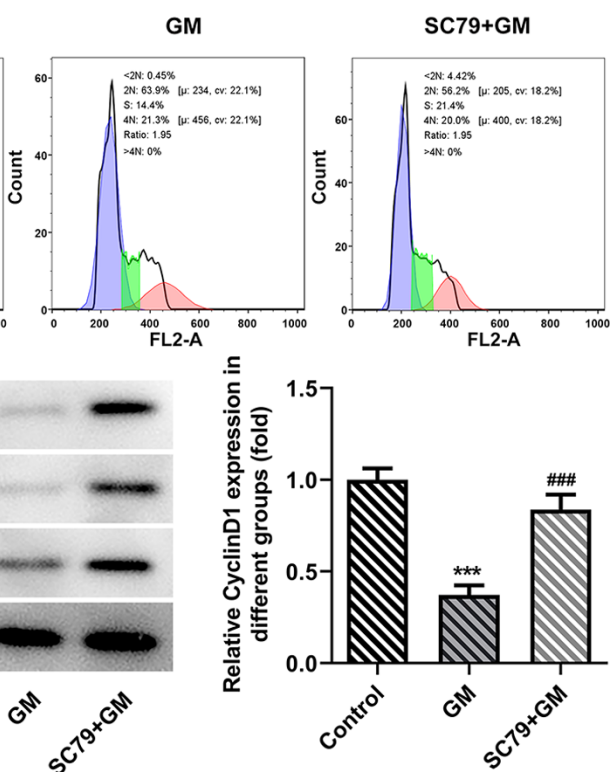

B
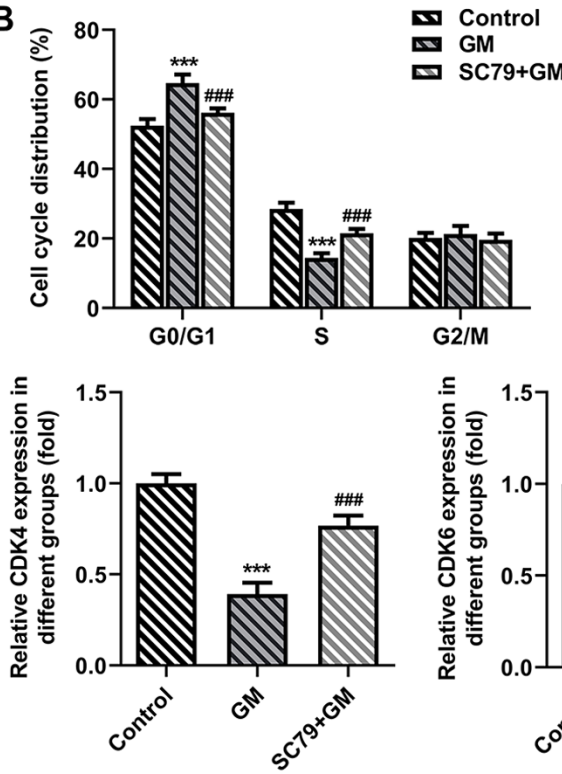

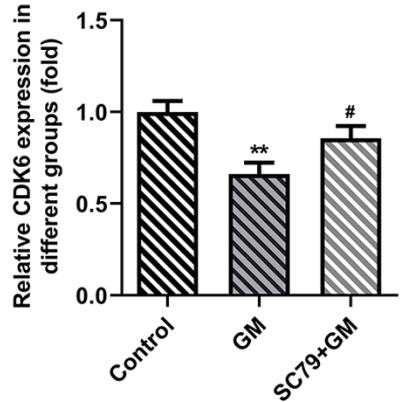

Figure 7. SC79 reverses the pro-cell cycle arrest effects of GM on lung cancer cells. Cell cycle distribution was (A) measured via flow cytometry and (B) quantified $(\mathrm{n}=3)$. $(\mathrm{C})$ Expression levels of cell cycle-related proteins were determined via western blotting $(\mathrm{n}=3) .{ }^{* * *} \mathrm{P}<0.01$ and ${ }^{* * * *} \mathrm{P}<0.001$ vs. control; ${ }^{*} \mathrm{P}<0.05$ and

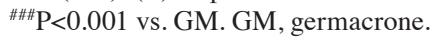
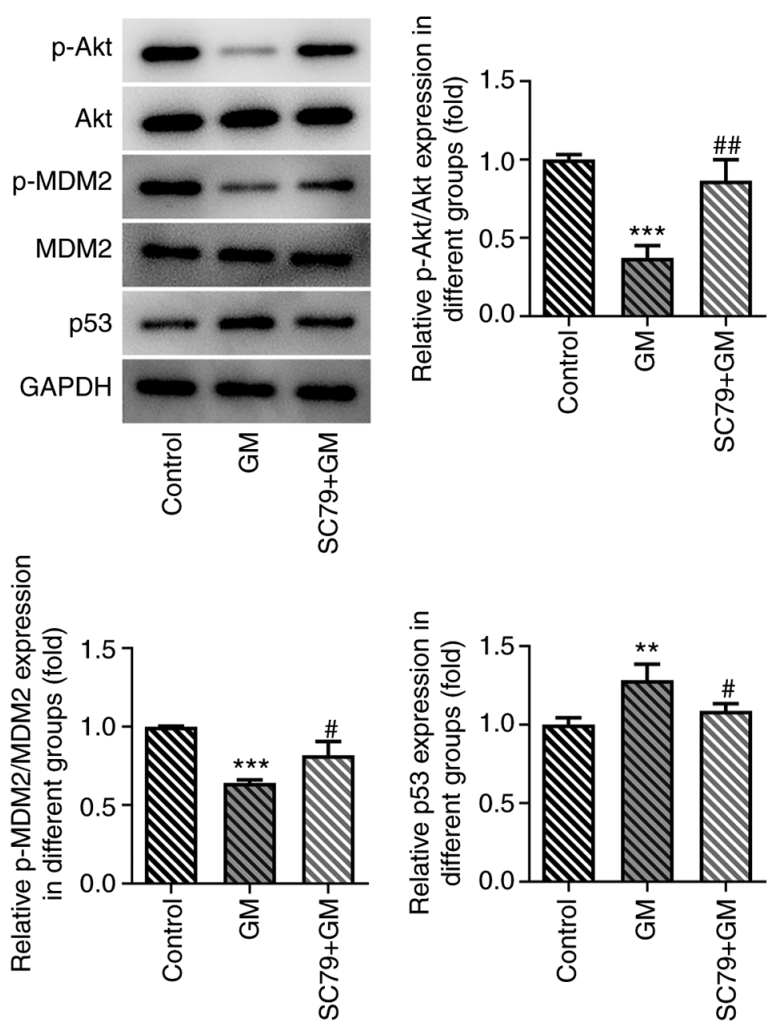

Figure 8 . Effect of SC79 on the Akt/MDM2/p53 signaling pathway. Expression levels of Akt/MDM2/p53 signaling pathway-related proteins were determined via western blotting. ${ }^{* *} \mathrm{P}<0.01$ and ${ }^{* * *} \mathrm{P}<0.001$ vs. control; ${ }^{\#} \mathrm{P}<0.05$ and ${ }^{\# \#} \mathrm{P}<0.01$ vs. GM. MDM2, MDM2 proto-oncogene; GM, germacrone; $\mathrm{p}$, phosphorylated.

\section{Discussion}

GM displays antiviral, antioxidant, anti-inflammatory and immunomodulatory pharmacological effects $(20,22)$.
Pharmacological studies have demonstrated that GM also displays antitumor effects on gastric cancer (4), glioma (21) and breast cancer (9) by inducing cell cycle arrest and promoting cell apoptosis. Cai et al (23) reported that curcumol extracted from zedoary enhanced celecoxib-induced growth inhibition and apoptosis in NSCLC. However, to the best of our knowledge, the effects of GM isolated from zedoary in lung cancer have not been previously reported. Therefore, the present study investigated the effects of GM on lung cancer cells. The results of the present study demonstrated that GM induced lung cancer cell apoptosis and cell cycle arrest, thereby inhibiting the development of lung cancer.

Following further investigation into the effects of GM on lung cancer cell apoptosis and cell cycle arrest and its molecular mechanism, the present study demonstrated that the expression levels of p-Akt and p-MDM2 were significantly downregulated, whereas the expression levels of p53 were significantly upregulated by different concentrations of GM (100 and $200 \mu \mathrm{M})$ compared with the control group. Malignancy in various different types of cancer cells (such as breast, ovarian epithelial, prostate and gastric cancer) is associated with increased abnormal Akt signaling (24). Akt phosphorylates the $\mathrm{p} 53$ suppressor MDM2, promoting nuclear translocation of MDM2, thereby inhibiting p53 (25). As a classical tumor suppressor gene, p53 mutations occur in $>50 \%$ of all malignant tumors (26). The protein encoded by $\mathrm{p} 53$ is a transcription factor that controls the initiation of the cell cycle, and regulates cell proliferation and apoptosis via a complex molecular network (27). It has been previously reported that the expression levels of p-Akt and p-MDM2 are upregulated in prostate cancer cells, which downregulates p53 expression and induces cell cycle arrest (28). Similarly, genistein inhibited esophageal cancer cell proliferation by inhibiting activation of the Akt/MDM2/p53 signaling pathway (13). 
Furthermore, GM induces prostate cancer cell apoptosis and autophagy by inhibiting the Akt/mTOR signaling pathway (8). GM can serve a role in breast cancer cells by targeting the estrogen receptor, MAPK, AKT and other signaling pathways $(29,30)$. The aforementioned studies suggested that GM could target the Akt signaling pathway. Following administration of SC79, the antiproliferative, proapoptotic and pro-cell cycle arrest effects of GM on lung cancer cells were significantly reversed. Collectively, the results of the present study demonstrated that GM induced lung cancer cell apoptosis and cell cycle arrest via the Akt/MDM2/p53 signaling pathway. However, it has been previously reported that GM can decrease the expression levels of $\mathrm{p}$-Akt in cerebral ischemia-reperfusion injury model rats, which was inconsistent with the results of the present study; therefore, future studies should investigate this inconsistency further (31).

A key limitation of the present study was that the therapeutic effect of GM on lung cancer was not studied in a mouse tumor model. Therefore, future studies should investigate the therapeutic effect of GM on lung cancer in vivo.

In conclusion, the present study demonstrated that GM promoted lung cancer cell apoptosis and cell cycle arrest by inhibiting the Akt/MDM2/p53 signaling pathway. The results of the present study provided a theoretical basis for identifying potential drugs and targets for the treatment of lung cancer.

\section{Acknowledgements}

Not applicable.

\section{Funding}

No funding was received.

\section{Availability of data and materials}

The datasets used and/or analyzed during the current study are available from the corresponding author on reasonable request.

\section{Authors' contributions}

YZ and JC contributed to the conception and design of the present study, analyzed and interpreted the data, and critically revised the manuscript for important intellectual content. KS, HL and JD contributed to designing the study, analyzed the data, and drafted and revised the manuscript. DH, ZL and WW substantially contributed to the conception and design of the study, acquired, analyzed and interpreted the data, and drafted and critically revised the manuscript for important intellectual content. YZ and JC confirm the authenticity of all the raw data. All authors read and approved the final manuscript.

\section{Ethics approval and consent to participate}

Not applicable.

\section{Patients consent for publication}

Not applicable.

\section{Competing interests}

The authors declare that they have no competing interests.

\section{References}

1. Rivera GA and Wakelee H: Lung Cancer in never smokers. Adv Exp Med Biol 893: 43-57, 2016.

2. Garon EB, Hellmann MD, Rizvi NA, Carcereny E, Leighl NB, Ahn MJ, Eder JP, Balmanoukian AS, Aggarwal C, Horn L, et al: Five-year overall survival for patients with advanced non-small-cell lung cancer treated with pembrolizumab: Results from the phase I KEYNOTE-001 study. J Clin Oncol 37: 2518-2527, 2019.

3. Chiang AC and Herbst RS: Frontline immunotherapy for NSCLC-the tale of the tail. Nat Rev Clin Oncol 17: 73-74, 2020.

4. Wu L, Wang L, Tian X, Zhang J and Feng H: Germacrone exerts anti-cancer effects on gastric cancer through induction of cell cycle arrest and promotion of apoptosis. BMC Complement Med Ther 20: 21, 2020.

5. Chen QF, Wang G, Tang LQ, Yu XW, Li ZF and Yang XF: Effect of germacrone in alleviating HUVECs damaged by H2O2-induced oxidative stress. Zhongguo Zhong Yao Za Zhi 42: 3564-3571, 2017 (In Chinese).

6. Wang Z, Zhuo F, Chu P, Yang X and Zhao G: Germacrone alleviates collagen-induced arthritis via regulating Th1/Th2 balance and NF- $\mathrm{B}$ activation. Biochem Biophys Res Commun 518: $560-564,2019$.

7. Nair A, Amalraj A, Jacob J, Kunnumakkara AB and Gopi S: Non-curcuminoids from turmeric and their potential in cancer therapy and anticancer drug delivery formulations. Biomolecules 9: 13, 2019.

8. Yu Z, Xu J, Shao M and Zou J: Germacrone induces apoptosis as well as protective autophagy in human prostate cancer cells. Cancer Manag Res 12: 4009-4016, 2020.

9. Zhong Z, Chen X, Tan W, Xu Z, Zhou K, Wu T, Cui L and Wang Y: Germacrone inhibits the proliferation of breast cancer cell lines by inducing cell cycle arrest and promoting apoptosis. Eur J Pharmacol 667: 50-55, 2011.

10. An JF, Sun Y, Zhang QL, Zhang FL and Zhang JL: The effects of germacrone on lipopolysaccharide-induced acute lung injury in neonatal rats. Cell Mol Biol (Noisy-le-Grand) 60: 8-12, 2014.

11. Hashem S, Nisar S, Sageena G, Macha MA, Yadav SK, Krishnankutty R, Uddin S, Haris M and Bhat AA: Therapeutic effects of curcumol in several diseases; An overview. Nutr Cancer 73: 181-195, 2021.

12. Xu W, Gao L, Li T, Zheng J, Shao A and Zhang J: Mesencephalic astrocyte-derived Neurotrophic factor (MANF) protects against neuronal apoptosis via activation of Akt/MDM2/p53 signaling pathway in a rat model of intracerebral hemorrhage. Front Mol Neurosci 11: 176, 2018.

13. Gao J, Xia R, Chen J, Gao J, Luo X, Ke C, Ren C, Li J and Mi Y: Inhibition of esophageal-carcinoma cell proliferation by genistein via suppression of JAK1/2-STAT3 and AKT/MDM2/p53 signaling pathways. Aging (Albany NY) 12: 6240-6259, 2020.

14. Chen H, Zhou L, Wu X, Li R, Wen J, Sha J and Wen X: The PI3K/AKT pathway in the pathogenesis of prostate cancer. Front Biosci (Landmark Ed) 21: 1084-1091, 2016.

15. Iida M, Harari PM, Wheeler DL and Toulany M: Targeting AKT/PKB to improve treatment outcomes for solid tumors. Mutat Res 819-820: 111690, 2020.

16. Song M, Bode AM, Dong $Z$ and Lee MH: AKT as a therapeutic target for cancer. Cancer Res 79: 1019-1031, 2019.

17. Reyes-Farias M and Carrasco-Pozo C: The Anti-Cancer Effect of Quercetin: Molecular implications in cancer metabolism. Int J Mol Sci 20: 3177, 2019.

18. Chen G, Park D, Magis AT, Behera M, Ramalingam SS, Owonikoko TK, Sica GL, Ye K, Zhang C, Chen Z, et al: Mcl-1 Interacts with Akt to promote lung cancer progression. Cancer Res 79: 6126-6138, 2019.

19. Mayo LD and Donner DB: A phosphatidylinositol 3-kinase/Akt pathway promotes translocation of $\mathrm{Mdm} 2$ from the cytoplasm to the nucleus. Proc Natl Acad Sci USA 98: 11598-11603, 2001.

20. Xie XH, Zhao H, Hu YY and Gu XD: Germacrone reverses Adriamycin resistance through cell apoptosis in multidrug-resistant breast cancer cells. Exp Ther Med 8: 1611-1615, 2014. 
21. Liu B, Gao YQ, Wang XM, Wang YC and Fu LQ: Germacrone inhibits the proliferation of glioma cells by promoting apoptosis and inducing cell cycle arrest. Mol Med Rep 10: 1046-1050, 2014

22. He W, Zhai X, Su J, Ye R, Zheng Y and Su S: Antiviral Activity of Germacrone against Pseudorabies Virus in vitro. Pathogens 8: 258, 2019.

23. Cai F, Chen M, Zha D, Zhang P, Zhang X, Cao N, Wang J, He Y, Fan X, Zhang W, et al: Curcumol potentiates celecoxib-induced growth inhibition and apoptosis in human non-small cell lung cancer. Oncotarget 8: 115526-115545, 2017.

24. Revathidevi S and Munirajan AK: Akt in cancer: Mediator and more. Semin Cancer Biol 59: 80-91, 2019.

25. Abraham AG and O'Neill E: PI3K/Akt-mediated regulation of p53 in cancer. Biochem Soc Trans 42: 798-803, 2014.

26. van Oijen MG and Slootweg PJ: Gain-of-function mutations in the tumor suppressor gene p53. Clin Cancer Res 6: 2138-2145, 2000.

27. Flemming A: Cancer: Mutant p53 rescued by aggregation inhibitor. Nat Rev Drug Discov 15: 85, 2016.
28. Han CT, Schoene NW and Lei KY: Influence of zinc deficiency on Akt-Mdm2-p53 and Akt-p21 signaling axes in normal and malignant human prostate cells. Am J Physiol Cell Physiol 297: C1188-C1199, 2009.

29. Lim MS, Choung SY and Jeong KW: Germacrone inhibits estrogen receptor $\alpha$-mediated transcription in MCF-7 breast cancer cells. Phytother Res 30: 2036-2043, 2016.

30. Kong Q, Ma Y, Yu J and Chen X: Predicted molecular targets and pathways for germacrone, curdione, and furanodiene in the treatment of breast cancer using a bioinformatics approach. Sci Rep 7: 15543, 2017.

31. Wu T, Yin F, Kong H and Peng J: Germacrone attenuates cerebral ischemia/reperfusion injury in rats via antioxidative and antiapoptotic mechanisms. J Cell Biochem 120: 18901-18909, 2019.

This work is licensed under a Creative Commons Attribution-NonCommercial-NoDerivatives 4.0 International (CC BY-NC-ND 4.0) License. 